\title{
Occurrence and habitat preference of aquatic macrophytes in a large river channel
}

\author{
A. I. Engloner ${ }^{1,4}$, E. Szalma ${ }^{2}$, K. Sipos ${ }^{3}$ and M. Dinka ${ }^{1}$ \\ ${ }^{1}$ MTA Centre for Ecological Research, Danube Research Institute, Vácrátót, Hungary \\ ${ }^{2}$ Department of Geography and Ecotourism, Faculty of Education, University of Szeged, \\ Hungary \\ ${ }^{3}$ Danube-Ipoly National Park Directorate, Budapest, Hungary \\ ${ }^{4}$ Corresponding author; engloner.attila@okologia.mta.hu, engloner@elte.hu
}

Keywords: large river, Lemna, Potamogeton, Secchi transparency, water flow velocity

Citation: Engloner, A.I., Szalma, E., Sipos, K., Dinka, M. 2013. Occurrence and habitat preference of aquatic macrophytes in a large river channel. Community Ecology, 14:243248.

\begin{abstract}
This paper explores correlations between macrophyte occurrence and environmental characteristics recorded in a more than $350 \mathrm{rkm}$ long segment of the main Danube channel in Hungary. The selected river section belongs entirely to the lowland part of the Middle Danube, but it is separated into the mostly gravelly upper and the sandy lower river sections. Two markedly different groups of macrophytes correlated with this separation; the mostly perennial, rooting species (Myriophyllum spicatum, Potamogeton crispus, $P$. nodosus, $P$. pectinatus, $P$. perfoliatus and Zannichellia palustris) preferred the gravelly habitats, while the non-rooting, free-floating macrophytes (Cabomba caroliniana, Ceratophyllum demersum, Lemna minor, Salvinia natans and Spirodela polyrhiza) occurred mainly in the sandy stretches. Based on the current velocity and Secchi transparency, these stretches seemed to provide "more lotic" and "rather lentic" habitats. Data evaluation also revealed that the closer are the river stretches to a water course discharging upstream the more free-floating aquatic plants occur in the main Danube channel.
\end{abstract}

Abbreviations: JDS - Joint Danube Survey; MIDCC - Multifunctional Integrated Study Danube Corridor and Catchment; rkm — river kilometre; SU — survey unit.

Nomencalture: Simon (2000).

\section{Introduction}

Studies intending to identify main factors explaining macrophyte occurrence or searching for correlations between species abundance and environmental parameters in large rivers, like the Danube, face several difficulties. On one hand, human impacts (such as river regulation, bank stabilization, navigation and urbanization, agricultural and 
industrial activities) constantly endanger and alter habitats and make ecosystems highly complicated (Birk et al. 2012). Furthermore, vegetation assessment is often sparse and does not cover the entire length of the hundreds of kilometres long river channels while the evaluation of macrophyte data can be problematic in several aspects (Podani 2006, Engloner 2012).

One of the most significant assessments along the Danube was the survey organized by the International Commission for the Protection of the Danube River (ICPDR) in order to collect environmental and biological data from sample points designated along the navigable section of the river. The second Joint Danube Survey (JDS-2) collected records from more than 70 official JDS sites based on what the LDC (least-disturbed condition) sites were defined, the differences between macrophytes of LDC and non-LDC stretches were described and alternative benchmarking was introduced (Birk et al. 2012). Relationships between macrophyte distribution and water flow velocity at those JDS sites were also studied (Janauer et al. 2010). Detailed macrophyte assessments of entire water bodies (streams, oxbows or long river sections) were accomplished by the international project MIDCC (Multifunctional Integrated Study Danube Corridor and Catchment). Based on the collected data, significant differences in macrophyte occurrence were revealed mainly between water courses with different connectivity types (Janauer and Steták 2003, Otahelova et al. 2007).

The number and abundance of the species observed in large rivers are often low. In fact, aquatic macrophytes may be totally absent from considerably long river sections. Further problems can arise during data evaluation if relevant variables (concerning, for example, species abundance, water conditions and bank structure) are recorded on different scales (i.e. nominal, ordinal or metric scales). If so (and in most cases this is the situation), methods for data evaluation have to be selected carefully, otherwise one reveals data structure that does not exist (Podani 2005, 2006). Abundance scores of macrophytes are, for instance, frequently recorded on ordinal scale. Therefore, methods suitable to ordinal data are necessary or values have to be converted to metric scale. In the first case, information is lost when species abundances are reduced to presence/absence data, while in the second case mathematical procedures available for metrizing ordinal scores may significantly affect the dataset and the results (Engloner 2012).

The present study aims to provide an appropriate evaluation of the macrophyte data recorded in the Hungarian Danube section during the MIDCC project and reveals correlations between plant occurrence and environmental characteristics in a more than $350 \mathrm{rkm}$ long segment of the main channel. The selected river section provides an exciting object for this study; it belongs entirely to the lowland part of the Middle Danube, but it is markedly separated into two parts; the mostly gravelly upper and the sandy lower river sections (Töry 1952).

\section{Materials and methods}

Field survey

Data analysed in this paper were gathered from the main Danube channel in Hungary; on the right river bank between the 1786-1709 rkms and on both river banks between the $1708-1433 \mathrm{rkms}$. Along the $628 \mathrm{~km}$ long bank section in total, macrophyte 
abundances and environmental conditions were assessed in one-kilometre-long stretches as survey units (SU's) (Janauer and Steták 2003, Sipos 2003, 2004, Szalma 2004, Szalma and Szalma 2003) during the field studies of the international project MIDCC. To estimate the relative abundance of species in river sections, a five-level descriptor scale was used (known as 'Kohler method') in which the ordinal statements were 1, rare; 2, occasional; 3, frequent; 4, abundant; 5, very abundant (Kohler et al. 1971, Kohler 1978).

In the field, some environmental variables, such as bank structure and sediment types, water flow velocity and Secchi transparency were also recorded. For describing the first two environmental characteristics, 1-6 classes were used (namely 1: large blocks or stones; 2: gravel; 3: sand; 4: fine inorganic substrate; 5: concrete or other artificial material and 6: floating mats for bank structure classification and 1: solid rock; 2: gravel; 3: sand; 4: fine inorganic substrate; 5: artificial material and 6: detritus or other organic material for sediment characterisation). Details on Kohler method and environmental categories have been published in the MIDCC guidance: "Manual Methodology for running water" (www.midcc.at).

\section{Data evaluation}

Environmental characteristics recorded in the field confirmed the well-known separation of the investigated Danube channel; except for large blocks and stones covering the main part ( $42 \%$ ) of the river bank, the mostly gravelly upper and the sandy lower sections were clearly separated (Engloner et al. 2013). Therefore, we tested whether survey units group similarly on the basis of macrophyte occurrence. Nineteen macrophyte species recorded with very different frequencies were involved in data evaluation (Table 1). None of the species reached the highest abundance score (i.e. Kohler value 5) along the river section (for detailed presentation of habitat characteristics and species abundance scores along the Hungarian Danube channel, see Engloner et al. 2013). The ordinal scores were converted to metric scale following Engloner (2012); the metric values substituting the 1-5 Kohler's (i.e. rare, occasional, frequent, abundant and very abundant) states were $3 ; 15 ; 37.5 ; 62.5$ and 87.5. The converted scores were analysed by standardized Principal Components Analysis (SYN-TAX 2000 package, Podani 2001).

Possible background factors behind the species distribution were also investigated. Besides the habitat characteristics recorded during the field survey, a further environmental variable; the distances between survey units and the nearest water courses (side branches, streams or channels, for instance) discharging upstream into the main channel were involved. The fact that the different environmental variables and species abundance values were on different scales (namely on nominal: bank structure and sediment types; on ordinal: species abundance scores and on ratio scale: Secchi transparency and distances from discharging water courses) makes revealing correlations between these variables difficult. To solve this problem mathematically, variables on ordinal and ratio scales should be converted into nominal states which would result loss of information. Instead, we provided visual picture on the relationships between the habitat conditions and macrophyte occurrence in a way that abundance scores were plotted against environmental characteristics. To avoid overlapping points and make the 
Table 1.

Macrophytes involved in data evaluation with the abbreviations of names and the numbers of river stretches in which the species occurred.

\begin{tabular}{lll}
\hline Species & abbreviation & $\begin{array}{l}\text { No of } \\
\text { stretches }\end{array}$ \\
\hline Cabomba caroliniana & Cab car & 12 \\
Ceratophyllum demersum & Cer dem & 38 \\
Elodea canadensis & Elo can & 6 \\
Hydrocharis morsus-ranae & Hyd mor & 1 \\
Lemna gibba & Lem gib & 1 \\
Lemna minor & Lem min & 43 \\
Lemna trisulca & Lem tri & 1 \\
Myriophyllum spicatum & Myr spi & 18 \\
Myriophyllum verticillatum & Myr ver & 2 \\
Najas marina & Naj mar & 1 \\
Persicaria amphibia & Per amp & 4 \\
Potamogeton crispus & Pot cri & 27 \\
Potamogeton lucens & Pot luc & 1 \\
Potamogeton nodosus & Pot nod & 10 \\
Potamogeton pectinatus & Pot pec & 100 \\
Potamogeton perfoliatus & Pot per & 20 \\
Salvinia natans & Sav nat & 6 \\
Spirodela polyrhiza & Spi pol & 28 \\
Zannichellia palustris & Zan pal & 28 \\
\hline
\end{tabular}

numbers of cases visible, abundance scores were jittered (low numbers (10-2) were added randomly to the scores, so that one value does not obscure another).

\section{Results}

As the result of PCA shows, stretches of the two river sections differing in sediment type clearly separated on the basis of macrophyte abundance (Fig. 1). Variance between the survey units was higher in the lower than in the upper river section. Macrophytes, except for species with very low frequency (i.e. occurring only in a couple of stretches, see Table 1), were also arranged into two groups: Myriophyllum spicatum, Potamogeton crispus, $P$. nodosus, $P$. pectinatus, $P$. perfoliatus and Zannichellia palustris compose the first group, while Cabomba caroliniana, Ceratophyllum demersum, Lemna minor, Salvinia natans and Spirodela polyrhiza compose the other. Separation of stretches can be explained well by these two macrophyte groups: the former is associated with the upper section, while the latter with the lower river section.

Fig. 2 shows the abundance scores of four selected species plotted against some environmental characteristics. They were the most frequent representatives of the two macrophyte groups separated in Fig.1; the two Potamogeton species were chosen from the first, while $L$. minor and $C$. demersum from the second. Occurrence of macrophytes 


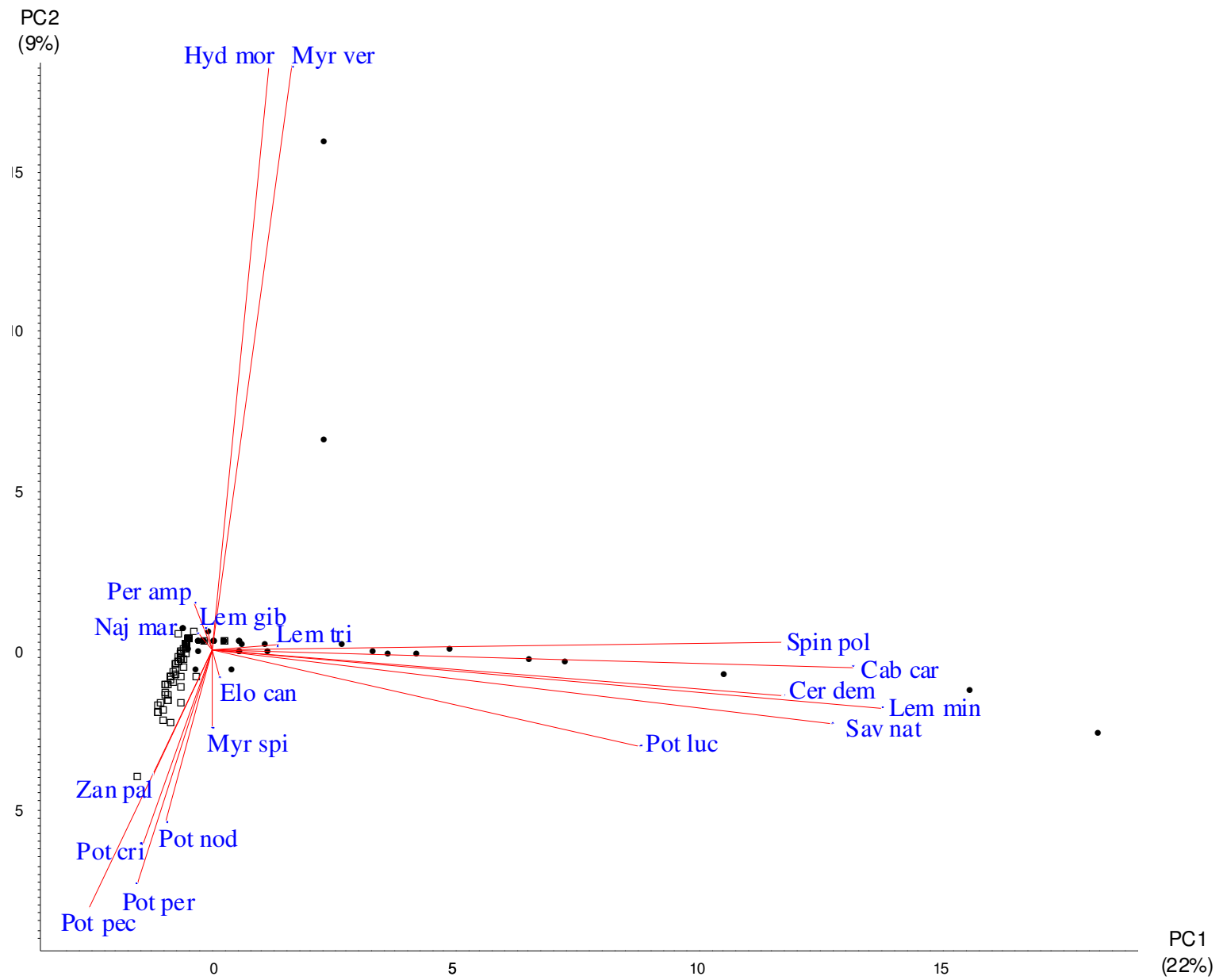

Fig. 1. Biplot of PCA based on the converted abundance values. Species are represented by abbreviations as listed in Table 1 . Symbols for objects (stretches) refer to the upper (open squares) and lower (filled circles) river sections which the survey units belong to.

separated well on the basis of bank structure. Except for category 1, i.e. large blocks and stones found frequently along the whole river section, Potamotegon species preferred SU's with gravelly banks (category 2), while Lemna and Ceratophyllum species occurred mostly in stretches where banks were covered by sand or fine inorganic material (categories 3and 4). Based on sediment structure, exactly the same tendency was observed.

The further environmental characteristics presented in Fig. 2 also separated the two macrophyte groups. Potamogeton species were most frequent in waters with around $70 \mathrm{~cm}$ Secchi values, while Lemna and Ceratophyllum preferred $40-50 \mathrm{~cm}$ transparency. The distance from discharging water courses seemed to have effects only on Lemna and Ceratophyllum species; they were more frequent and had higher abundance scores in SU's closer to the inflowing waters. Contrarily, frequencies and abundances of Potamogeton species seemed to be similar in SU's situated in various distances from inflow waters. 

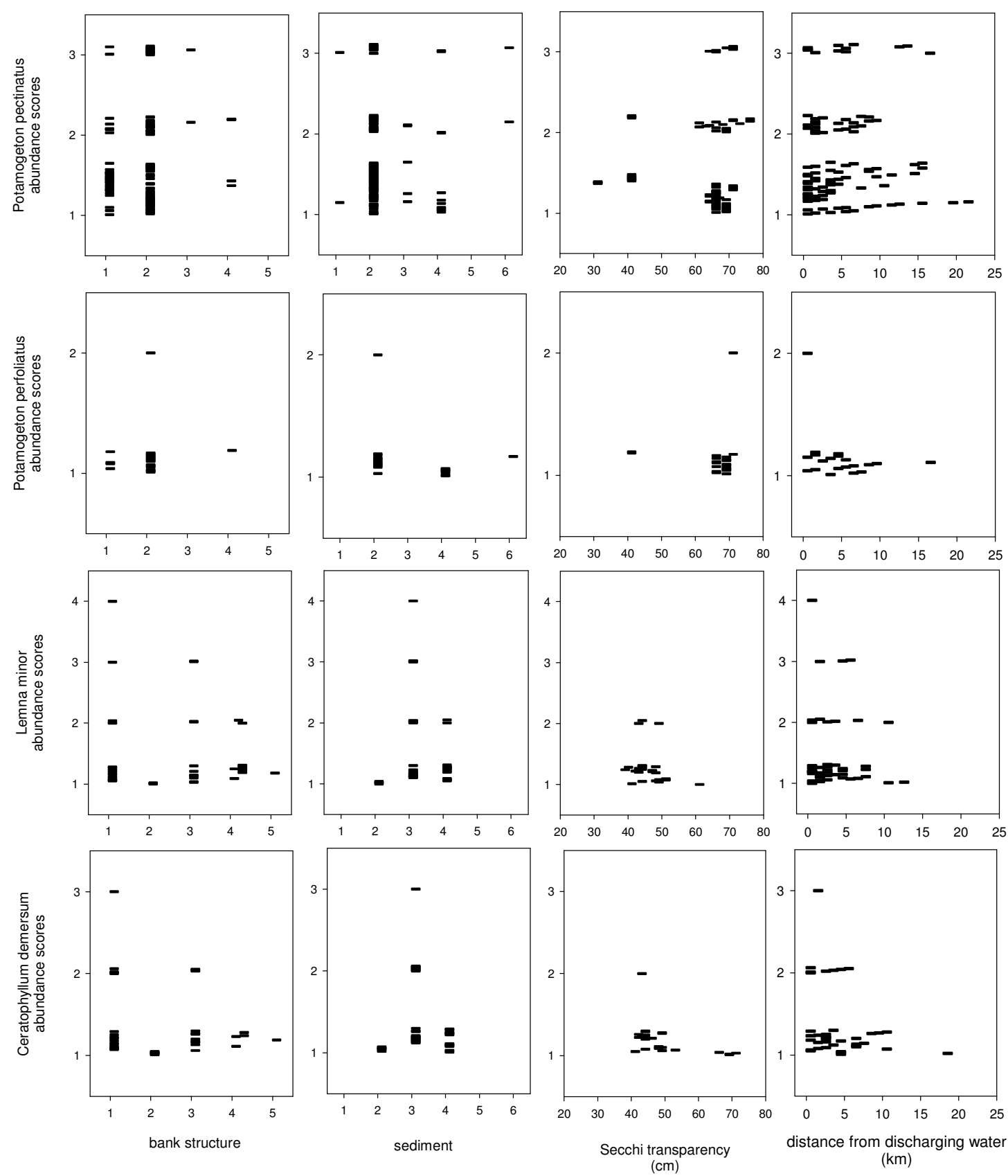

Fig. 2. Abundance scores of four macrophytes plotted against environmental characteristics. Nominal statements of bank structure and sediment types are 1: large blocks, stones or solid rocks; 2: gravel; 3: sand; 4: fine inorganic substrate; 5: concrete or other artificial material and 6: detritus or other organic material. The same abundance scores were jittered (pulled away by low numbers (10-2) added randomly to the values). One thin horizontal mark represents one occurrence. 


\section{Discussion}

Despite the low presence of macrophytes and the various scales on which the variables were recorded, the results revealed clear tendencies and correlations between the occurrence of plant species and habitat characteristics. The two channel sections differing in bank structure and sediment content were related to two different groups of species. Noticeably, macrophytes belonging to the same group have the same life-forms as well. In the gravelly upper river stretches, mostly perennial, rooting species (Myriophyllum, Zannichellia and Potamogeton) occurred which attach to the substrate and overwinter with rhizomes, runners or tubers in the sediment (Barrat-Segretain 1996). These species are aquatic cryptophytes or hydrophytes, according to the Raunkiaer system. Contrarily, in the sandy lower Danube section, the non-rooting, free-floating macrophytes (i.e. the hydro-therophytes: Ceratophyllum, Lemna, Salvinia and Spirodela) were frequent.

Of course, the two categories of habitats; the gravelly and the sandy river stretches incorporate a complex variety of environmental variables. Substrate may affect macrophytes in several ways; organic content, redox potential, nutrient availability are, for example, relevant characteristics (Bornette and Puijalon 2011, Franklin et al. 2008). Furthermore, sediment may also refer to water flow velocity which is thought to be among the strongest environmental variables determining the occurrence and/or abundance of aquatic plants (Franklin et al. 2008, Janauer et al. 2010). It is well known that rivers are unable to carry the gravel under a certain level of velocity; therefore, sand and fine inorganic substrates replacing downstream the gravel in the investigated river section indicate lower water flow velocity in the lower river section. In fact, the speed of water higher in gravelly than in sandy river stretches was proved by field measurements from the same Danube section (Erös et al. 2005).

The observed rooting macrophytes (Myriophyllum, Zannichellia and Potamogeton species) seem to prefer gravelly habitats with faster water flow. At first glance, this result contradicts the general supposition that high current velocity and coarse-grained material of banks and bottom make the environment unsuitable for vascular aquatic plants (Madsen et al. 2001, Franklin et al. 2008, Otahelova et al. 2008). However, the experiment (Chambers et al. 1991) cited in the literature found that 'at current speeds in excess of $1 \mathrm{~m} / \mathrm{s}$, aquatic macrophytes were rare'. In this manner, habitats with flow velocities below the above threshold may host different macrophyte communities. Janauer et al. (2010) found, among other species, Potamogeton perfoliatus and $P$. pectinatus to be indicators for habitats with 'no visible flow'. The latter authors used a four-point scale (1: no flow/stagnant; $2: 5-30 \mathrm{~cm} / \mathrm{s}, 3: 31-69 \mathrm{~cm} / \mathrm{s} ; 4: \geq 70 \mathrm{~cm} / \mathrm{s}$ ) when analyzed the data set of JDS-2 and revealed significant differences in species occurrence only between fast flowing river sections (flow class 4) and SU's with 'no visible flow' (flow class 1). Character species were revealed only in these two cases, while intermediate flow classes had no indicator plants. Almost the same four-point scale was used in MIDCC projects (see MIDCC guidance: www.midcc.at) and, in the case of the Hungarian Danube section, the classification revealed no differences between the stretches; $97 \%$ of the investigated SU's belonged to flow class 2 ('low flow from just visible to ca. $30 \mathrm{~cm} / \mathrm{s}^{\prime}$ ) (Engloner et al. 2013). However, measurements performed along the Danube channel in Hungary, as mentioned above, revealed differences; in water depths of $0.3-1.4$ metres, the average current velocities were between $5-60 \mathrm{~cm} / \mathrm{s}$ in 
gravelly, and 0-10 cm/s in sandy SU's (Erös et al. 2005, and Erös pers. comm.). These values can be in line with Chambers et al. (1991)'s findings and draw the attention to the fact that relatively small variability in flow velocity (smaller than detectable by visual categories) may cause relevant differences in macrophyte occurrence.

Water transparency is a further environmental variable that can be related to the substrate of river bed, since it can be reduced by fine sediment. According to the records, Secchi values were higher in gravelly habitats of rooting species than in the sandy stretches where free-floating macrophytes were frequent.

Based on the above results, the investigated Danube channel seems to provide two different; a "more lotic" and a "rather lentic" habitats which may have its own characteristic macrophyte vegetation. Rooting macrophytes (occurring mainly in habitats with gravelly river bed with faster water flow and higher transparency) are certainly able to establish stable and permanent stands in river environments due to the underground organs they use to draw back during the winter and to develop again in spring. (Of course, pollution and other harmful anthropogenic factors may diminish or exclude the occurrence of these species.) In contrast, the non-rooting and free-floating macrophytes do not have the above organs, which rises the question whether seeds and shoot fragments, for instance, are sufficient sources for their establishment in a large river channel or if there is another reason for their occurrence? The evaluation of macrophyte data along the main Danube channel in Hungary revealed that the closer the river stretches to a water course discharging upstream the more free-floating aquatic plants (Ceratophyllum and Lemna, e.g.). This result, which is in line with Janauer and Steták (2003)'s findings indicates that small inflowing waters may carry these macrophytes into the main channel, but these species can remain or can be frequent in "rather lentic" habitats of the river. Interestingly, rooted macrophytes were absent in this sort of habitats.

To answer why this is, and also to reveal further environmental characteristics and anthropogenic pressure (cf. Birk et al. 2012) in detail that may affect macrophyte occurrence in the gravelly and sandy stretches require further experiments. Nevertheless, our results demonstrated detectable tendencies in macrophyte occurrence along a considerable part of the lowland Middle Danube. It is worth considering that if the presence of macrophytes is low and the recorded environmental variables are on various scales (as it is often in case of large river studies), a simple visualization of data set could be more effective than sophisticated mathematical procedures altering the data structure in an unknown way.

Acknowledgements: Field surveys providing macrophyte abundance data were supported by the international project MIDCC. Thanks to Dóra Steták for data placed at our disposal. This work was partially funded by the Hungarian Scientific Research Grant (OTKA K106177). A.I. Engloner was supported by the János Bolyai Research Scholarship of the Hungarian Academy of Sciences. 


\section{References}

Barrat-Segretain, M.H. 1996. Strategies of reproduction, dispersion, and competition in river plants: A review. Vegetatio 123:13-37.

Birk, S., Van Kouwen, L. and Willby, N. 2012. Harmonising the bioassessment of large rivers in the absence of near-natural reference conditions - a case study of the Danube River. Freshwater Biol. 57:1716-1732.

Bornette, G. and Puijalon, S. 2011. Response of aquatic plants to abiotic factors: a review. Aquat. Sci. 73:1-14.

Chambers, P.A., Prepas, E.E., Hamilton, H.R. and Bothwell, M.L. 1991. Current velocity and its effect on aquatic macrophytes in flowing waters. Ecol. Appl. 1:249-257.

Engloner, A.I. 2012. Alternative ways to use and evaluate Kohler's ordinal scale to assess aquatic macrophyte abundance. Ecol. Indic. 20:238-243.

Engloner, A.I., Szalma, E., Sipos, K., and Dinka, M. 2014. Distribution and habitat characteristics of macrophyte vegetation in the Middle Danube (1786-1433 rkm), Hungary. In: Janauer, G.A., Květ, J., Germ, M., and Gaberščik, A., (eds.), Aquatic Macrophytes of the River Danube Basin. Academia Prague Publishers (in press).

Erös, T., Sevcsik A. and Tóth, B. 2005. Abundance and night-time habitat use patterns of Ponto-Caspian gobiid species (Pisces, Gobiidae) in the littoral zone of the River Danube, Hungary. J. Appl. Ichthyol. 21:350-357.

Franklin, P., Dunbar, M. and Whitehead, P. 2008. Flow controls on lowland river macrophytes: A review. Sci. Total Environ. 400:369-378.

Janauer, G. A., Schmidt-Mumm, U. and Schmidt, B. 2010. Aquatic macrophytes and water current velocity in the Danube River. Ecol. Eng. 36:1138-1145.

Janauer, G.A. and Steták, D. 2003. Macrophytes in the Hungarian lower Danube valley (1498-1468 river-km). Large Rivers Vol. 14. Arch. Hydrobiol. 147:167-180.

Kohler, A. 1978. Methoden der Kartierung von Flora und vegetation von Süßwasserbiotopen. Landschaft Stadt. 10:73-85.

Kohler, A., Vollrath, H. and Beisl, E. 1971: Zur Verbreitung, Vergesellschaftung und Ökologie der Gefaß-Makrophyten im Fließ wassersystem Moosach (Münchener Ebene). Arch. Hydrobiol. 69:333-356.

Madsen, J.D., Chambers, P.A., James, W.F., Koch, E.W. and Westlake, D.F. 2001. The interaction between water movement, sediment dynamics and submersed macrophytes. Hydrobiologia 444:1-84.

Otahelova, H., Valachovic, M. and Hrivnak, R. 2007. The impact of environmental factors on the distribution pattern of aquatic plants along the Danube River corridor (Slovakia). Limnologica 37:290-302.

Podani, J. 2001. SYN-TAX 2000. Computer Programs for Data Analysis in Ecology and Systematics. User's Manual. Scientia, Budapest.

Podani, J. 2005. Multivariate exploratory analysis of ordinal data in ecology: pitfalls, problems and solutions. J. Veg. Sci. 15:497-510.

Podani, J. 2006. Braun-Blanquet's legacy and data analysis in vegetation science. J. Veg. Sci. 17:113-117.

Simon, T. 2000. A magyarországi edényes flóra határozója. Nemzeti Tankönyvkiadó, Budapest. 
Sipos, K. 2003. Survey on Danube 1786 - 1659 rkm. Macrophyte Inventory Danube / Corridor and Catchment - MIDCC. Preliminary Partner Report - Hungary, pp. 117. (manuscript)

Sipos, K. 2004. Survey on Szentendrei-Danube and Danube 1658 - $1588 \mathrm{rkm}$. Macrophyte Inventory Danube / Corridor and Catchment - MIDCC. Preliminary Partner Report - Hungary, pp. 1-26. (manuscript)

Szalma, E. 2004. Survey on Danube main channel 1518 -1498 rkm and 1468-1433 (Border) rkm. Macrophyte Inventory Danube / Corridor and Catchment - MIDCC, Annual Partner Report -Hungary, pp. 1-25. (manuscript)

Szalma, E. and Szalma, J. 2003. Danube main channel rkm 1587-1518. Macrophyte Inventory Danube / Corridor and Catchment - MIDCC. Preliminary Partner Report - Hungary, pp. 1-24. (manuscript)

Tőry, K. 1952. A Duna és szabályozása. (The Danube and its regulation.) Akadémiai Kiadó, Budapest. 